\title{
INTERSEASONAL HEAT STORAGE FOR RESIDENTIAL BUILDINGS WITH RENEWABLE ENERGY GENERATION
}

Janar Kalder, Mart Hovi, Alo Allik, Andres Annuk

Estonian University of Life Sciences, Estonia

janar.kalder@emu.ee,mart.hovi@emu.ee, alo.allik@emu.ee, andres.annuk@emu.ee

\begin{abstract}
This article describes the modelling of the energy system for a house, which includes components for heating, electricity production from renewables, energy storage and consuming devices. The electrical energy production devices are not connected to the electrical power supply grid and overproduced energy is stored in along term storage water tank. Batteries are also included in the energy system. The energy production of the PV-panels in spring, summer and early autumn is high but the annual heat energy demand for a house is nearly zero. Therefore, it is sensible to use the power plant in grid connected mode and the grid acts like a storage, where is it possible to sell the overproduced energy. The aim of this research is to investigate a solution that uses as much as possible of the produced energy locally, storing the energy in the vacuum insulated tank as heat, if batteries are full. The energy that is stored in the tank, can be used at the beginning of the heating season. This article is based on modelling of the proposed heating system. The inputs for the model are production data from PV panels and a wind generator, climate data (outside temperature) and the heat and electricity demand of the example house. Storing overproduced energy as heat in the vacuum insulated tank, will increase the share of locally produced energy, and therefore decrease import of electrical and other sources of energy. The results show, if the yearly renewable energy production is $13000 \mathrm{~kW} \cdot \mathrm{h}$ and the house yearly energy demand is $12981 \mathrm{~kW} \cdot \mathrm{h}$, then over $79 \%$ of overall energy demand can be covered from renewable energy sources, if the solar/wind share is $30 / 70 \%$. With the solar/wind ratio $70 / 30 \%$, the coverage is over $60 \%$.
\end{abstract}

Keywords: solar energy, wind energy, long term storage tank, seasonal storage, vacuum insulation.

\section{Introduction}

Energy from the sun can be used to increase the share of renewable energy for heating of a house. The use of solar energy is widely investigated for heating systems, like the use of solar collectors and different other methods for using it effectively [1], for example, increasing the coefficient of performance (COP) of a heat pump [2]. Solar energy is mostly available in warmer periods, when the heating demand is low. Therefore, it is necessary to use interseasonal storages for heat energy. Previously borehole storages have been investigated [3;5], large tanks and basins and etc. [5]. However, these are large storages or complex technology (phase change materials) [6] and using them for a single family house would not be efficient. For increasing the consumption of electricity, which is produced locally with a wind generator and photovoltaic (PV) panels, also different methods are previously investigated. For example, batteries [7], demand management [8], preheat boilers [9;10] and other systems are used. However, these methods are not feasible to store enough energy for the long term heating of a house.

Earlier research for increasing the share of renewable energy for heating a house used only solar collectors and a medium size vacuum insulated tank (VSI tank). The results showed that the direct heating percentage from solar energy for a $160 \mathrm{~m}^{2}$ house can be $41 \%$ in a system with a $15 \mathrm{~m}^{3}$ storage tank [11]. Direct heating means in this case that the energy is used directly, without converting it. The VSI tank contains an outer and an inner tank. The space between these layers is filled with expanded perlite and air is evacuated [12]. The VSI tank U-value is $0.05 \mathrm{~W} \cdot \mathrm{m}^{-2} \cdot \mathrm{K}^{-1}[13]$ and measurements, in the test period, showed an $0.23 \mathrm{~K}$ average temperature drop per day, when placed outdoor [14].

In Nordic countries, the amount of energy used for house heating is high. For covering both, the electricity and heating demands, it is necessary to use both storage systems (interseasonal storage and batteries). The new approach is to use PV-panels, a wind generator, batteries and a VSI tank together to increase the renewable energy share for a single-family house. The remaining energy after covering the demand of electricity for household devices and daily energy for domestic hot water (DHW) is stored in to the VSI tank and used during the heating season. The aim of this research is to investigate how much is it possible to cover from the overall energy demand of a house with renewable energy sources in different wind and solar energy production conditions, when consumption and production are similar. One requirement of this system is that all produced electricity is used locally, in vicinity 
without selling it to the AC grid. The system also is usable in locations without a distribution grid. The system is suitable for nearly zero buildings.

\section{Materials and methods}

This research is based on a model, which is based on the energy system of a small building. The model is made with spreadsheet software, where all necessary parameters of the heating and consuming systems are used for making calculations. The system overview is shown in Figure 1. The input parameters for the model are the production of wind and solar energy, consumption of household electricity, energy spent for domestic hot water and the energy demand for heating. Production of wind and solar energy is based on the measurements between 01.12. 2015 and 30.11.2016. The rated power of the wind generator is $10 \mathrm{~kW}$, which is located in a coastal area (N 59.087694, E 23.591719) and manufactured by Tuge Ltd. Photovoltaic panels rated power is $2.5 \mathrm{~kW}$, the producer is DelSolar (DelSolar $250 \mathrm{~W}$ DP250B3A). In Estonian territory the PV panel capacity factor 0.11 is quite even.

The demand of household electricity is based on the measurements conducted during October 2018. The measuring interval was one hour and the data are converted to 5 minute averages. These data are taken 12 times to get the electricity consumption for one year, which is total $4623 \mathrm{~kW} \cdot \mathrm{h}$. The energy for heating is based on the calculated two storey house, which floor area is $160 \mathrm{~m}^{2}$ and surface area $434 \mathrm{~m}^{2}$. The average $\mathrm{U}$-value $0.17 \mathrm{~W} \cdot \mathrm{m}^{-2} \cdot \mathrm{K}^{-1}$, indoor temperature $21^{\circ} \mathrm{C}$, free heat $3 \mathrm{~W} \cdot \mathrm{m}^{-2}$ and the outdoor temperature, measurement step 5 minutes, are taken for calculating the demand of heat energy. The DHW is equal with the energy, which is needed to rise a temperature of 1501 water in the boiler from $5{ }^{\circ} \mathrm{C}$ to $70^{\circ} \mathrm{C}$. For simplification, the heat capacity of construction materials is not taken into account. For covering deficit of electricity, when renewable energy is not available, energy is taken from the AC grid, using automatic switch between the energy sources.

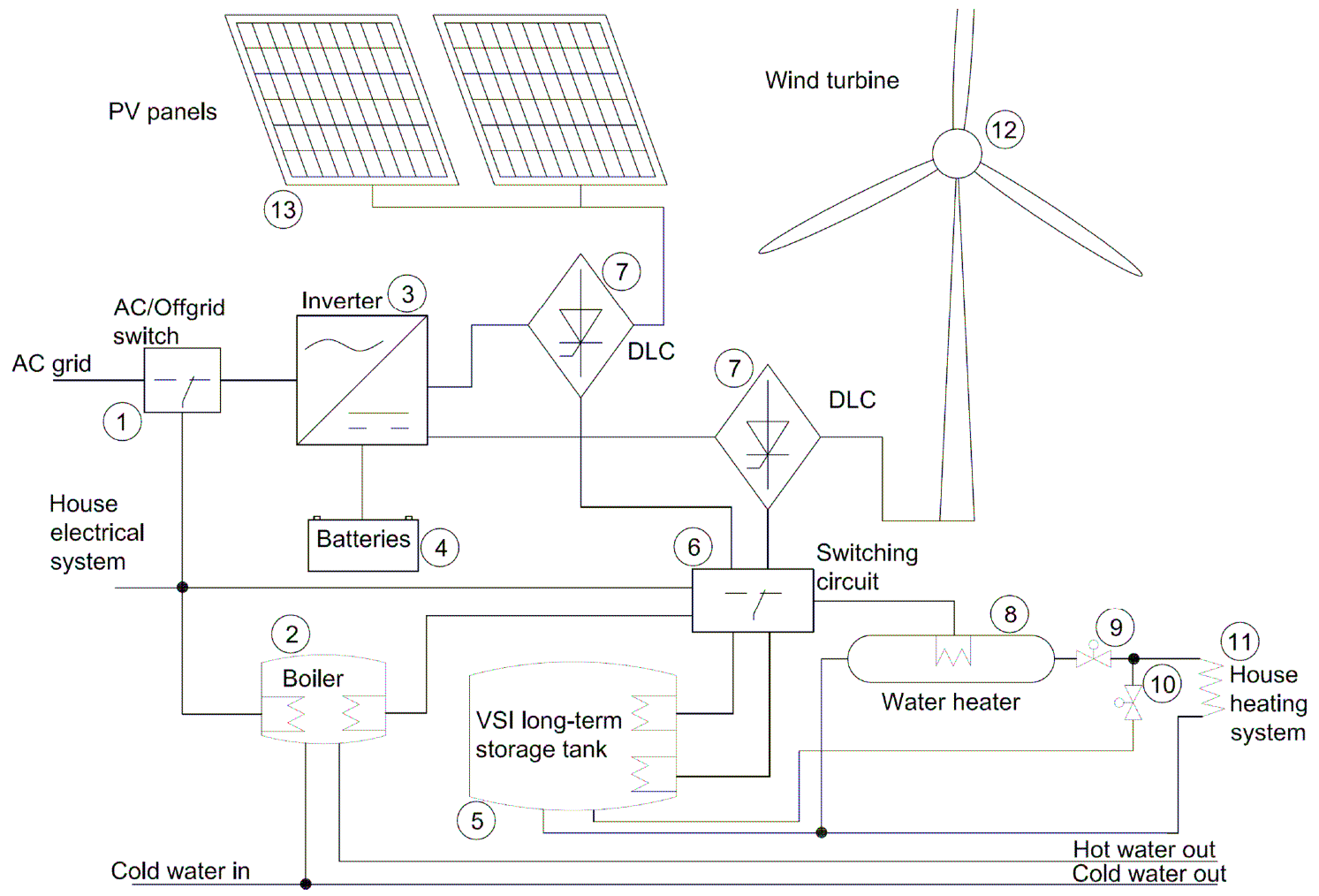

Fig. 1. Circuit diagram of energy system of house: 1 - AC grid connection; 2 - boiler for DHW;

3 - inverters for solar panels and wind generator; 4 - batteries; 5 - long-term storage tank;

6 - microcontroller controlled switch; 7 - dump load controllers (DLC) for solar panels and the wind generator; 8 - water heater for the heating system; 9,10 - heating supply switching valves;

11 - floor heating supply; 12 - wind generator; 13 - PV panels

The modelling is based on energy amounts of 5 minute intervals. Firstly, the produced renewable energy is used to cover the household's electricity demand and charge the deep cycle batteries with a 
capacity of $9.6 \mathrm{~kW} \cdot \mathrm{h}(200 \mathrm{Ah}, 48 \mathrm{~V})$. Energy from the batteries is used until $36 \%$ depth of discharge (DoD) is reached. The charging current of the batteries is limited to $20 \mathrm{~A}$, which is in accordance with the rule of thumb that the charging current should not exceed $0.2 \mathrm{C}$, where $\mathrm{C}$ is the batteries capacity (Ah). The remaining energy is directed to the boiler, after that directly into the heating system of the house and after that to the VSI tank. The energy, which is added to the VSI tank and boiler, causes a temperature change described by formula 1 :

$$
t=t_{p}+\frac{Q_{\Re}-\sum Q_{\text {loss }}-\sum Q_{\text {con }}}{m_{w} c_{w}}
$$

where $t$ - water temperature, ${ }^{\circ} \mathrm{C}$;

$t_{p}$ - previous water temperature, ${ }^{\circ} \mathrm{C}$;

$Q_{r e}$ - renewable energy, $\mathrm{kW} \cdot \mathrm{h}$;

$Q_{\text {loss }}-$ energy losses, $\mathrm{kW} \cdot \mathrm{h}$;

$Q_{\text {con }}$ - energy consumption, $\mathrm{kW} \cdot \mathrm{h}$;

$m_{w}-$ water weight, $\mathrm{kg}$;

$c_{w}$ - water specific heat, $\mathrm{kW} \cdot \mathrm{h} \cdot \mathrm{kg}^{-1} \cdot \mathrm{K}^{-1}$.

From the energy that goes into the boiler the energy of heat loss is taken off and energy for DHW. The AC grid is used for supply of the boiler, when the temperature drops under $40^{\circ} \mathrm{C}$. This temperature is taken experimentally. If the temperature in the boiler raises over $70^{\circ} \mathrm{C}$, then energy flows directly to heating the house, if needed, and then remaining energy goes to the VSI tank. From the energy that goes into the VSI tank, the energy of heat loss is taken off and the energy for house heating, if the temperature inside the tank is over $34^{\circ} \mathrm{C}$. This temperature is the minimum for floor heating supply. The maximum temperature of the VSI tank $\left(15 \mathrm{~m}^{3}\right)$ is $100{ }^{\circ} \mathrm{C}$, although up to $110{ }^{\circ} \mathrm{C}$ is also acceptable due to higher than atmospheric pressure[13]. Maximum pressure of the VSI tank is 3 bar [13]. The energy loss of the tank is calculated by using the outdoor temperature. The energy for house heating is taken from the $\mathrm{AC}$ grid, when the temperature in the tank drops under $34^{\circ} \mathrm{C}$.

The outputs from PV panels and the wind generator are fluctuating and therefore it is necessary to use variable heaters for the boiler, the VSI tank and water heater. This is achieved by using multiple 3 phase heaters and by switching them according to the renewable energy productivity to match the different loads.

The outputs of production devices are scaled to get different energy productions in the range of 2$15 \mathrm{~kW} \cdot \mathrm{h}$. The proportions of solar and wind energy are changed between 100:0, 70:30, 50:50, 30:70, $0: 100$. This enables to research how the productivity of PV-panels and the wind generator affects the energy balance of the house. To get these data, the special program is written, which changes the renewable energy production device scale in the model and collects all necessary output parameters. The output parameters of the model, which are of interest, are: the renewable energy share of the house, direct heating share, energy loss and the renewable energy share of the household's electricity consumption. Loss of energy contains the unused energy and heat losses from the boiler and VSI tank.

\section{Results and discussion}

The yearly energy demand of the house is $12981 \mathrm{~kW} \cdot \mathrm{h}$, which includes household electricity $(4623 \mathrm{~kW} \cdot \mathrm{h})$, heat energy $(5613 \mathrm{~kW} \cdot \mathrm{h})$ and energy for DHW $2745 \mathrm{~kW} \cdot \mathrm{h}$.

The results of the modelling show that the best result is achievable, when only a wind generator is used (Fig. 2). However, the loss of energy is smallest in a configuration, where the renewable energy share of the house demand is over $0.77(10000 \mathrm{~kW} \cdot \mathrm{h} \cdot \mathrm{a})$ and $30 \%$ are produced from wind and $70 \%$ from solar energy (Fig. 4). The share of renewable energy is significantly lower, when using this option, compared with the option, when all energy is produced by the wind generator. The renewable energy share in the household electricity consumption is better, when both energy production devices are used (Fig. 5).

In a situation, when the ratio between the renewable energy production and consumption of the house is 1 and the solar/wind share is $30 / 70 \%$, the share of directly consumed renewable energy was $79 \%(10313 \mathrm{~kW} \cdot \mathrm{h})$. Energy losses were in this scenario $21 \%(2747 \mathrm{~kW} \cdot \mathrm{h})$, of which $2292 \mathrm{~kW} \cdot \mathrm{h}$ were energy losses from the VSI tank and the boiler. The remaining energy loss $(455 \mathrm{~kW} \cdot \mathrm{h})$ was 
caused by unused renewable energy and inefficiency of the batteries. The energy from the VSI tank that was used to heatthe house is $3346 \mathrm{~kW} \cdot \mathrm{h}$ and deficit of energy that was taken from the AC grid, was $2649 \mathrm{~kW} \cdot \mathrm{h}$.

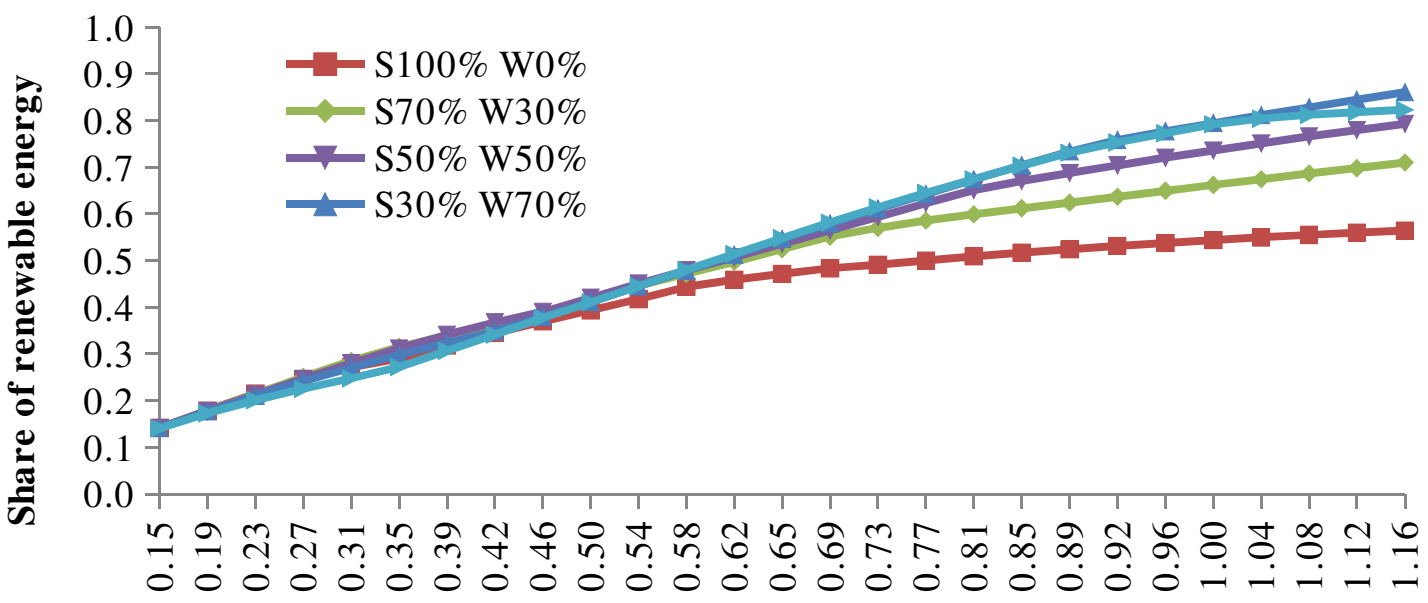

Ratio of renewable energy production to house demand

Fig. 2. Share of renewable energy of house electricity supply

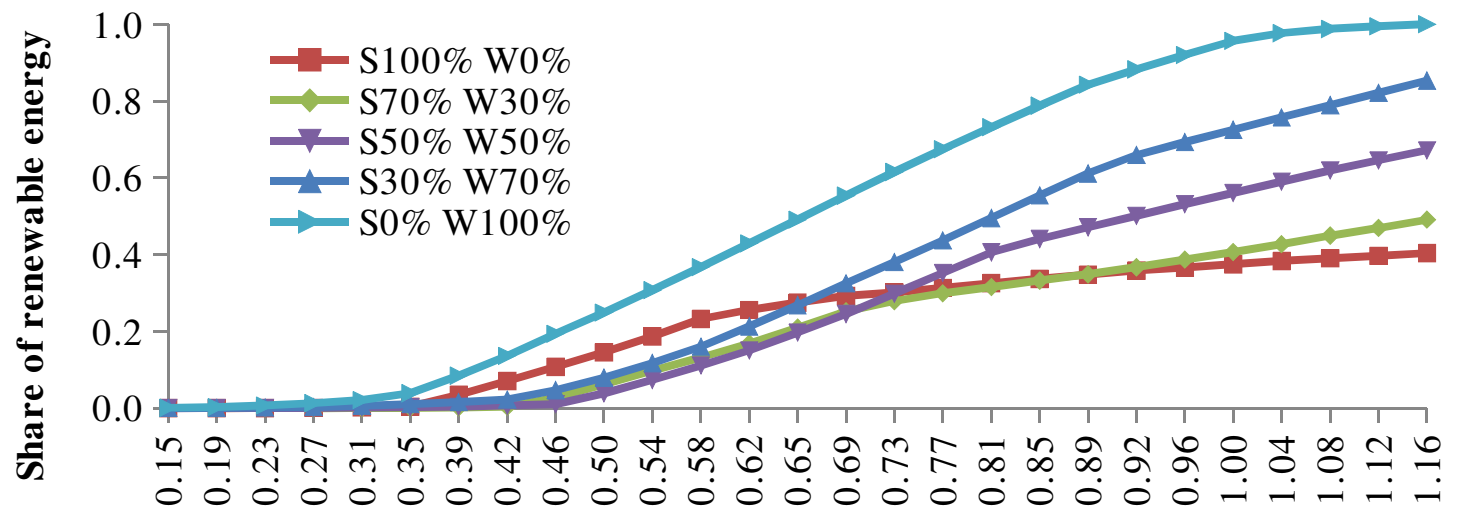

Ratio of renewable energy production to house demand

Fig. 3. Share of renewable energy for direct heating of house

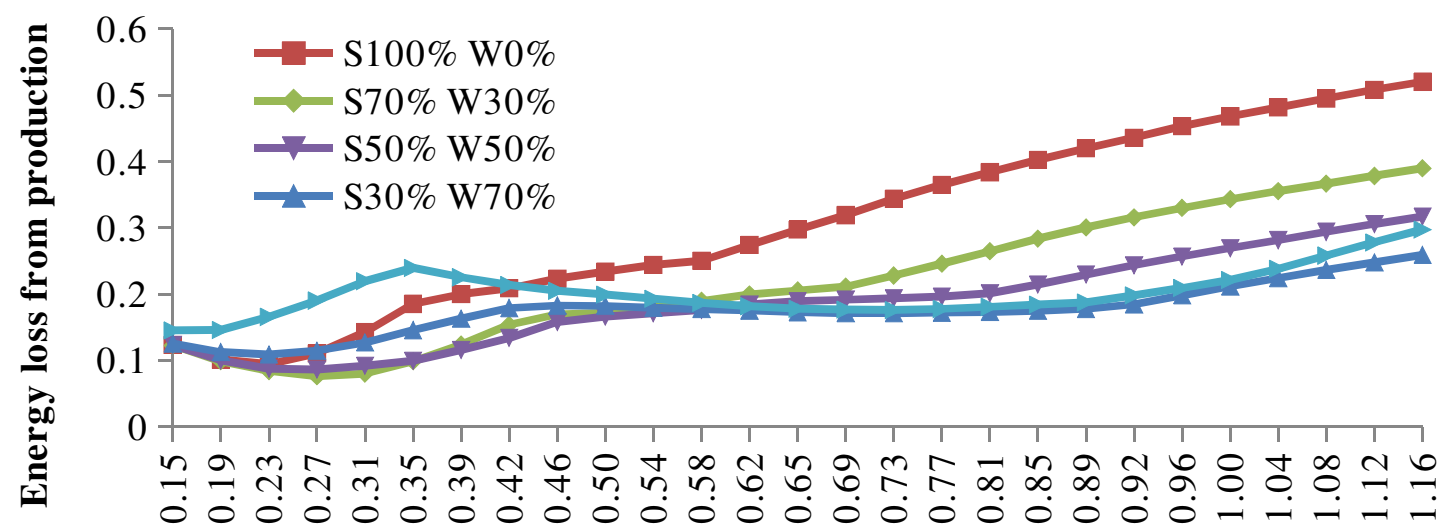

Ratio of renewable energy production to house demand

Fig. 4. Energy loss of system 
This all in one system is new and actual to supply the house with electrical and heat energy. Also investments for other electrical consuming heating devices, like a ground source heat pump, are not needed, because the energy demand from the AC grid is comparably small $(2649 \mathrm{~kW} \cdot \mathrm{h})$.

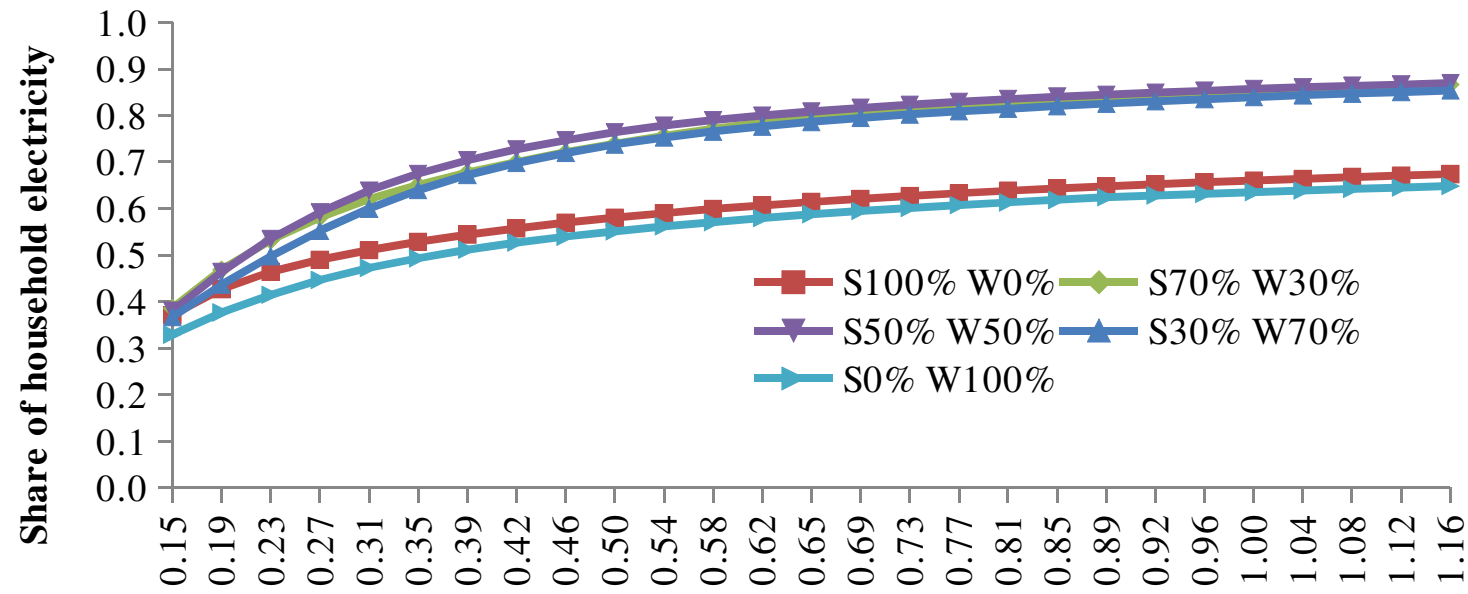

Produced energy, $\mathrm{kW} \cdot \mathrm{h}$

Fig. 5. Renewable energy share for household electricity

However, it is necessary take into consideration that the power from the wind generator is fluctuating, which is caused by climatic factors. Therefore, it is advisable to use a system, where $70 \%$ of the energy is generated from the PV panels and $30 \%$ from the wind. This covers directly over $60 \%$ of the overall energy consumption, if the produced amount of renewable energy is $13000 \mathrm{~kW} \cdot \mathrm{h}$, which is comparable to the total energy consumption. It is necessary to use renewable energy to meet the nearly zero energy building standard.

\section{Conclusions}

The following conclusions were made on the basis of the methodology given above:

1. It is possible to cover most of the energy demand of a house from the sun and wind, by using a vacuum insulated tank as long-term heat storage and when the production and demand are similar. Therefore, it is not necessary to build an additional heating system,like a ground source heat pump, because the amount of the purchased electricity isnegligible.

2. The share of directly consumed energy dependson the production of energy from PVpanels and the wind generator and the relationship between these energy amounts.

3. This approach for supplying the house with renewable energy enables to meet the requirements of the standard for nearly zero buildings.

\section{Acknowledgements}

This research was supported by the Estonian Centre of Excellence in Zero Energy and Resource Efficient Smart Buildings and Districts, ZEBE, grant 2014-2020.4.01.15-0016 funded by the European Regional Development Fund.

\section{References}

[1] Kalogirou S. A. Solar thermal collectors and applications. Progress in Energy and Combustion Science, vol. 30, 2004, pp. 231-295.

[2] Chwieduk D. A. Solar-assisted heat pumps. Comprehensive Renewable Energy, vol. 3, 2012, pp. 495-528.

[3] Lanahan M., Tabares-Velasco P. C. Seasonal thermal-energy storage: A critical review on BTES systems, modeling, and system design for higher system efficiency. Energies 2017, 10, 743.

[4] Bär K., Rühaak W., Welsch B. etc. Seasonal High Temperature Heat Storage with Medium Deep Borehole Heat Exchangers. Energy Procedia, vol. 76, 2015, pp. 351-360. 
[5] Novo A. V., Bayon J. R., Castro-Fresno D. etc. Review of seasonal heat storage in large basins: Water tanks and gravel-water pits. Applied Energy, vol. 87, 2010, pp. 390-397.

[6] Xu J., Wang R. Z., Li Y. A review of available technologies for seasonal thermal energy storage. Sol. Energy, vol. 103, 2014, pp. 610-638.

[7] Hassan A. S., Cipcigan L., Jenkins N. Optimal battery storage operation for PV systems with tariff incentives q. Appl. Energy, vol. 203, 2017, pp. 422-441.

[8] Zhang D., Shah N., Papageorgiou L. G. Efficient energy consumption and operation management in a smart building with microgrid. Energy Conversion and Management, vol. 74, 2013, pp. 209-222.

[9] Annuk A., Jogi E., Kalder J., Allik A. Evaluating electricity self-consumption in different renewable energy supply conditions. Proceedings of International Scientific Conference "Engineering for Rural Development", May 23-25, 2018, Jelgava, Latvia, vol. 17, pp. 1704-1709.

[10] Annuk A., Erkki J., Hovi M. etc. Increasing self electricity consumption by using double water heating tanks for residential net zero energy buildings.Proceedings of "International Conference on Renewable Energy research and Application (ICRERA)", October 14-17, 2018, Paris, France, vol. 6, pp. 106-110.

[11] Kalder J., Annuk A., Allik A. etc. Increasing Solar Energy Usage for Dwelling Heating, Using Solar Collectors and Medium Sized Vacuum Insulated Storage Tank. Energies, 2018, vol. 11, no. 7, p. 1832.

[12] Fuchs B., Hofbeck K., Faulstich M. On vacuum insulated thermal storage. Energy Procedia, 2012, vol. 30, pp. 255-259.

[13] Vacuum storage. Technical data. [online][01.03.2019]. Available at: http://vacuumstorage.com/series-vacuum-high-power.html?file $=$ files/downloads/technischedatenblaetter/en/TechData_VacuumHighPower.pdf

[14] Beikircher T., Buttinger M., Demharter M. etc. SuperisolierterHeißwasserLangzeitwärmespeicher :Abschlussberichtzu BMU-ProjektFörderkennzeichen 0325964A, Projektlaufzeit: 01.05.2010 - 31.10.2012. 2013. [online][01.03.2019]. Available at: https://edocs.tib.eu/files/e01fb13/7497011881.pdf. (In German). 